\title{
Mean platelet volume measurements affecting evaluation of parameters in dialysis patients (The affective of mean platelet volume)
}

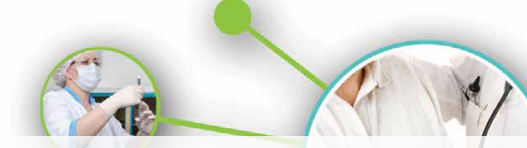

Background: We aimed to show the levels of mean platelet volum and also; the existence of effects parameters was investigated on mean platelet volum levels; in patients with dialysis replasman treatment.

Materials: This study was included to the control group and patients with peritoneal dialysis and patients with hemodialysis treatments and their dialysis adequate were ensured. Venous blood samples were taken from all of the cases and mean platelet volum levels, platelet, hemoglobin, insulin resistance, C- peptide and biochemical parameters were measured.

Results: Insulin resistance and C-peptid levels were found higher in the control group than in the dialysis groups. Platelet levels were found significiantly higher in dialysis groups than the control group and platelet levels were determined to be higher in the peritoneal dialysis group than the patients with hemodialysis group. Mean platelet volum levels were found higher in the dialysis patient groups than the control group. No difference statistical was observed for the levels of mean platelet volum; between dialysis groups. The relationship between was not shown to the levels of mean platelet volum with other parameters; in patients with dialysis treatment. Positive correlation was found the between platelet counts with mean platelet volum; in the control group.

Conclusion: We thought that the precence of end stage renal disease and dialysis therapies might cause to increase of mean platelet volum levels; in dialysis patients. This condition can be explained by the increase of atherosclerotic complication risk and inflammation risk; in dialysis patients.

KEYWORDS: Femodialysis, mean platelet volume, peritoneal dialysis

\section{Introduction}

Currently it is known that morbidite and mortality risk increase in patients with hemodialysis and peritoneal dialysis treatment; compared with general population. Cardiovascular diseases are an important risk factor for increase of morbidity and also; they can lead to death in dialysis patients. Additionally; vascular calcification, inflammation hyperparatiroidism and arteriel stifness may cause to the development of inflammation and atheroscklerosis and thereby; they contribute to the increase of morbidity; in the every stage of chronic renal diseases $[1,2]$.

The association between is shown to be continuous chronic inflammation with the development of cardiovascular diseases; in dialysis patients. It is thought that the precence of chronic inflammation might cause to continuous of progression of atheroscklerosis and this condition could contribute to the development of cardiovascular diseases; in the end-stage renal diseases. Also; it is known that the existence of relationship between uremia toxins with inflammation but their' effect mechanisms are not clearly explained; in dialysis patients $[3,4]$. İn some studies were shown that dialysis modality caused to the development of inflammation; by uremia toxins. This condition was explained that middle molecule uremic toxins and especially protein- bound uremic toxins are not adequate provide removal by dialysis modality.Because; the relationship between is found middle molecule uremic toxins and especially protein- bound uremic toxins with the development of hyperinflammation and progression of atheroscklerosis and the increase of cardiovascular disease risk [5]. Therefore; it is accepted that uremic toxins are an important risk factor for the development of inflammation and atherosclerosis.

The development of cardiovascular diseases are multifactoriel; in dialysis patients. Recently; mean platelet volum has been used as a biomarker to predict of cardiovascular diseases. It was determined in in-vitro studies that platelets
Nilgul Akalin*1, Mehmet Koroglu², Selcuk Sezikli, Senol Senturk ${ }^{4} \&$ Murat Asik $^{5}$

${ }^{1}$ Bakirkoy Dr Sadi Konuk Training and Research Hospital, Istanbul, Turkey

${ }_{2}^{2}$ Medical Park Medical School, Bakirkoy Street, Istanbul, Turkey

${ }^{3}$ Bakirkoy Dr Sadi Konuk Training and Research Hospital, Internal Medicine, Turkey

${ }^{4}$ Department of Obstetrics and Gynecology, Faculty of Medicine, Recep Tayyip Erdoğan University, Islampasa, Turkey

${ }^{5}$ Department of Radiology, Istanbul Universty Cerrahpasa Medical School, Turkey

*Author for correspondence:

Tel.: + 0905321200274

nilnef@hotmail.com 
became enzymatically and metabolically more active with increased platelet volume and they contained more prothrombotic materials. İncreased mean platelet volum contribute to the development of inflammation. Essentially; mean platelet volum levels effect on platelet activation and platelet function and atherotrombotic disease risk. However; the increase of mean platelet volum levels associated with elevated plasma Tromboxan B2 levels and shortened of bleeding time, increased ADP-associated aggregation response, prostacyclin-associated aggregation-inhibition[6,7].

It is shown that mean platelet volum can be effected by metabolic parameters and lifestyle such as age, gender, blood pressure, body mass index, alchol intake, smoking habits, lipid profils and fasting blood glucose $[8,9]$. Although; the increase of mean platelet volum levels associated with various metabolic disorders such as obesity, insulin resistance, prediabetes mellitus and diabetes mellitus.

Platelet function disorders can lead to bleeding and so they can cause to the development of anemia; in the every stage chronic renal disease. However; platelet function disorders contribute to the development of trombosis; especially in dialysis patients. Recently; it is tried to show the association between mean platelet volum levels with inflammation and atheroscklerosis but different results are gained. Some studies indicating that mean platelet volume levels in dialysis patient do not change in addition to the studies indicating presence of a negative correlation between reduced glomerular filtration rate and mean platelet volume $[10,11]$.

However; there is no consensus on the effects of MPV values in chronic kidney patients and dialysis patients [12].

We aimed to show the levels of mean platelet volum and also; the relationship between body mass index, insulin resistance, $\mathrm{C}$ - peptide and other biochemical parameters with mean platelet volüm; in patients with hemodialysis and peritoneal dialysis treatments. Apart from; the aim of this study was to demonstrate the levels of MPV could be an important indicator for the predict of cardiovascular diseases risk; in dialysis patients.

\section{Materials}

This study was approved by the Ethics Committee of Bakirkoy Dr. Sadi Konuk Training and Research Hospital (Grand number:
491/2014) and conducted in accordance with the principles of the Declaration of Helsinki. This study was not supported from any third party and the work was received any financial support.

Thirty peritoneal dialysis and 42 hemodialysis patients and 16 healty subjects aged 18-65 years who had followed-up and treated regularly and with adequate dialysis were included to the study. Histories of all patients were guestioned. Especially; the existence of acute inflammation (upper respiratory infection, pneumonia etc.), and chronic inflammation (collagen tissue disease, malignancy, diabetic foot etc.) were questioned because they can effect on platelet counts and cause to the development of platelet function disorders. During study; fever, cough, weight loss, joint pain and swelling etc. like the problems had patients; patients using antibiotics or chemotherapy were excluded from this study. Additionally; patients' physical muayne were made in order to exclude the presence acute and chronic inflammation. Diagnosis of diabetes mellitus ( once; fasting blood glucose $\geq 126$ $\mathrm{mg} / \mathrm{dl}$ or anytime; blood glucose $\geq 200 \mathrm{mg} / \mathrm{dl}$ had been accepted as diabetes mellitus ), obesite $\left(\mathrm{BMI} \geq 29.9 \mathrm{~kg} / \mathrm{m}^{2}\right)$, myocardial infarction (last six months) or ischemic cerebrovascular disease were excluded from the study. All patients in the dialysis group were measured urine output below 100-300 cc/day, therefore residual renal function was not evaluated. Weight and height of all cases were recorded and also; their' BMI (Body Mass Indices) were calculated. However; all participants were measured urea, creatinine, C- peptide, HOMA-IR (insulin resistance), LDL- cholesterol, HDL -cholesterol, hemoglobin, platelet, mean platelet volum. İn this study was aimed to show the relationship between mean platelet volume with urea, creatinine, C- peptide, HOMA-IR, LDLcholesterol, HDL - cholesterol, hemoglobin.

Hemodialysis patients were receiving fourhour dialysis replacement therapy three days in a week. Standard dialysate solutions (Na: 140 $\mathrm{mmol} / \mathrm{l}$; K: 0,1,2,3 mmol/l; $\mathrm{HCO}_{3:} 35 \mathrm{mmol} / \mathrm{l}$; $\mathrm{Cl}: 135 \mathrm{mmol} / \mathrm{l}$; Ca: $1.25-1.75 \mathrm{mmol} / \mathrm{l} ; \mathrm{Mg}$ : $0.5 \mathrm{mmol} / \mathrm{l}$ ) were used in hemodialysis patients but according to the patient' clinical and biochemical features were changed dialysate content. Biocompatible membrane polysulfone was used in hemodialysis patients. $\mathrm{Kt} / \mathrm{V}>1,4$ and URR> $70 \%$ were calculated to the patient with hemodialysis renal replasman treatment. The patients with peritoneal dialysis made a 
daily 4-6 exchanges with peritoneal dialysis solutions that they including $2000-2500 \mathrm{ml}$, $1.5 \%$ and $2.3 \%$ glucose and $1.25 \mathrm{mmol} / \mathrm{L}, 1.75$ $\mathrm{mmol} / \mathrm{L}$ calcium. The assessment of $\mathrm{Kt} / \mathrm{V}$ values of all peritoneal dialysis patients were 1.7 and greater had been fulfilled.

Body mass indices (BMI) of all patients were calculated. In the patients with dialysis treatment were evaluated dry weights. For this purpose, the following formula was used: BMI $(\mathrm{kg} / \mathrm{m} 2)=$ (body weight) $/$ (height) 2 .

Venous blood samples were taken from all of the patients included in the study after 12 hours of fasting and simultaneously and sent to the laboratory in appropriate conditions (without hemolysis etc.). Serum urea levels were measured by using Abbott ARCHITECTH device and Urease, Kinetic Method and serum creatinine levels were measured by using Abbott ARCHITECTH device and Alkaline Picrate method.

Serum insulin levels were calculated by Siemens Immulite 2000 device and Enzyme Chemiluminometric Immunoassay method used. Insulin resistance, Homeostasis Model Assessment (HOMA-IR) method was used to calculate insulin resistance and the values below $2.5 \mathrm{mmol} /$ litre were considered to be normal.

HOMA-IR = fasting plasma glucose $(\mathrm{mg} / \mathrm{dl})$ $\mathrm{x}$ fasting insulin level $(\mu \mathrm{U} / \mathrm{ml}) / 405$

C-peptide was studied with Siemens Immulite 2000 device using two-way Chemiluminometric Immunoassay method.Normal range was accepted as a $0.5-2.71 \mathrm{ng} / \mathrm{ml}$.

LDL-cholesterol levels were measured by using Abbott ARCHITECTH device and Immunoturbidimetric Method.

HDL- cholesterol levels were measured by using Abbott ARCHITECTH device and Nonimmunological method.

Hemoglobin values were studied with Beckman Coulter device using Beckman method.

Abbot, Cell Dyn Ruby device was used to the evaluation of platelet levels and mean platelet volum, in all cases. Normal range was accepted to the levels of platelet as a $100.000 \mathrm{~mm}^{3} / \mathrm{L}$ $300.000 \mathrm{~mm}^{3} / \mathrm{L}$. Normal value range of MPV levels was accepted as 7.4-12 femtolitres.

\section{Statistical Evaluation}

In this study, NCSS (Number Cruncher
Statistical System) 2007 (NCSS, LLC Kaysville, Utah, USA) package program was used for the statistical analysis.During the evaluation of the data obtained from the study, independent $t$ test was used for the intergroup comparisons of descriptive statistical methods (mean, standard deviation, inter quartile range) as well as comparisons of parameters with normal distribution, Oneway Anova test was used. Tukey HDS ve Games Howell tests were used to determine the groups causing the difference. Kruskal Wallis test was used for the comparisons of parameters without normal distribution. Mann Whitney $U$ test was used for the determination of the group causing difference and for the comparison of two groups. Pearson's and Spearman's correlation coefficients were used to determine the relationship between variables.

\section{Results}

This study was performed in Nephrology Clinic of Bakirkoy Dr Sadi Konuk Training and Research Hospital; between 2013 and 2014 years. This study was included the patients with hemodialysis treatment $(n=42,40.8 \%)$, peritoneal dialysis patients $(n=30,29.1 \%)$ and healty subjects $(n=16,15.5 \%)$ who had followed-up and treated regulary (TABLE 1).

Distribution of ages of all cases was found between 20-65 years and their' mean age was determined to $46.69 \pm 16.13$ years. Mean BMI of both the patient groups and control group was measured as a $24.60 \pm 4.95 \mathrm{~kg} / \mathrm{m}^{2}$. The betwen hemodialysis and peritoneal dialysis groups were not difference found; compared to dialysis durations (TABLE 2).

Statistically significantly difference was found to be the between BMI assesment of the groups; considering to the evaluation of Games- Howell test results $(\mathrm{p}=0.001 ; \mathrm{p}<0.01)$. The assesment of

Table 1. Distribution of cases in the dialysis groups and control group.

\begin{tabular}{|l|c|c|}
\hline & n & \% \\
\hline Control Group & 16 & 15.5 \\
\hline Hemodialysis Group & 42 & 40.8 \\
\hline Peritoneal Dialysis Group & 30 & 29.1 \\
\hline Oneway Anova Test & & \\
\hline
\end{tabular}

Table 2. Demographic and clinicical features in all groups.

\begin{tabular}{|l|c|c|}
\hline & Minumum- Maximum & Mean \pm SD \\
\hline Age (years) & $20-65$ & $46.69 \pm 16.13$ \\
\hline Body mass indices $\left(\mathrm{kg} / \mathrm{m}^{2}\right)$ & $17.16-33.90$ & $24.60 \pm 4.95$ \\
\hline Dialysis duration (years) & $0.50-9.00$ & $3.58 \pm 2.82$ \\
\hline Oneway Anova Test & &
\end{tabular}


BMI was found higher in the peritoneal dialysis group than in the hemodialysis and control group ( $\mathrm{p}=0.001 ; \mathrm{p}=0.014 ; \mathrm{p}<0.05)$ (TABLE 3).

The levels of urea were determined higher in the hemodialysis patient group than in the peritoneal dialysis patient group and control group $(p=0.005 ; p=0.001 ; p<0.01)$. The levels of creatinine were found higher in the hemodialysis and peritoneal dialysis groups than in the control group ( $\mathrm{p}=0.001 ; \mathrm{p}<0.01)$ (TABLE 3).

Compared to the groups; statistically significantly difference was found to be the between C- peptide levels. Mann- Whitney $\mathrm{U}$ test was used to the evaluation of Cpeptide levels and the levels of $\mathrm{C}$-peptide were determined higher in the hemodialysis and peritoneal dialysis groups than the control group $(p=0.001 ; p<0.01)$. The between of $\mathrm{C}$-peptide levels was not found difference; in hemodialysis and peritoneal dialysis patients ( $>$ 0.05) (TABLE 3).

İmportant differences were found between the groups; compared to the existence of insulin resistance $(p=0.002 ; p<0.01)$.Insulin resistance was found higher in the control group than in the dialysis groups $(\mathrm{p}=0.005 ; \mathrm{p}=0.045 ; \mathrm{p}<0.05)$ (TABLE 3).

Average LDL- cholesterol levels were found higher in peritoneal dialysis patients than in hemodialysis patients $(\mathrm{p}=0.002 ; \mathrm{p}<0.01)$ (TABLE 3).

Statistically significant difference was observed the between average HDL- cholesterol levels. The levels of HDL- cholesterol were found higher in the control group than in the hemodialysis group $(\mathrm{p}=0.009 ; \mathrm{p}=0.014$; $\mathrm{p}<0.05)$. No statistically significant difference was determined to the average HDL- cholesterol levels; in the peritoneal dialysis and control groups ( $p>0.05)$ (TABLE 3).

The platelet counts were determined higher in the hemodialysis and peritoneal dialysis groups than the control group and the average platelet counts were found higher in the peritoneal dialysis group than in the hemodialysis group; respectively $(\mathrm{p}=0.005 ; \mathrm{p}=0.001 ; \mathrm{p}=0.001$; $\mathrm{p}<0.01$ and $\mathrm{p}=0.001 ; \mathrm{p}<0.01)$ (TABLE 3).

Mean platelet volume (MPV) large levels were measured higher in the hemodialysis and peritoneal dialysis groups than control group and no statistically significant difference was observed between mean platelet volum large levels, in the dialysis groups; respectively $(\mathrm{p}=0.024 ; \mathrm{p}=0.001 ; \mathrm{p}=0.002 ; \mathrm{p}<0.05$ and $\mathrm{p}>0.05)$ (TABLE 3).

The relationship between was not demonstrated the levels of MPV large with the levels of urea, creatinine, hemoglobin, platelet, HOMA-IR, BMI, LDL- cholesterol, HDL

\begin{tabular}{|c|c|c|c|c|c|}
\hline & & Control Group $(n=16)$ & Hemodialysis Group ( $n=42$ ) & Peritoneal Dialysis Group $(n=30)$ & $\mathbf{p}$ \\
\hline \multirow{2}{*}{$\begin{array}{l}\text { Body mass index }(\mathrm{kg} / \\
\left.\mathrm{m}^{2}\right)\end{array}$} & Mean \pm Sd & $22.04 \pm 1.38$ & $22.43 \pm 2.86$ & $24.54 \pm 4.85$ & ${ }^{a} 0.001^{* *}$ \\
\hline & Median & 21.69 & 22.17 & 22.32 & \\
\hline Urea (mg/dl) & Median & 26.85 & 139.00 & 108.00 & \\
\hline Creatinine $(\mathrm{mg} / \mathrm{dl})$ & Mean \pm Sd & $0.88 \pm 0.11$ & $7.74 \pm 2.76$ & $8.64 \pm 2.69$ & ${ }^{c} 0.001^{* *}$ \\
\hline $\begin{array}{l}\text { C-peptide } \\
(\mathrm{ng} / \mathrm{ml})\end{array}$ & Median & 1.24 & 6.80 & 6.77 & \\
\hline \multirow{2}{*}{$\begin{array}{l}\text { İnsulin Resistance } \\
(\mathrm{mU} / \mathrm{ml})\end{array}$} & Mean \pm Sd & $1.88 \pm 0.63$ & $1.47 \pm 1.51$ & $1.94 \pm 2.19$ & ${ }^{c} 0.003^{* *}$ \\
\hline & Median & 1.88 & 0.74 & 1.01 & \\
\hline \multirow{2}{*}{$\begin{array}{l}\text { LDL- cholesterol (mg/ } \\
\text { dl) }\end{array}$} & Mean \pm Sd & $108.45 \pm 16.11$ & $96.34 \pm 39.06$ & $124.00 \pm 37.26$ & ${ }^{c} 0.012^{*}$ \\
\hline & Median & 107.00 & 91.50 & 122.50 & \\
\hline Hemoglobin (gr/dl) & Median & 11.90 & 10.10 & 10.50 & \\
\hline \multirow{2}{*}{$\begin{array}{l}\text { Platelet } \\
(\mathrm{m} \mu / \mathrm{l})\end{array}$} & Mean \pm Sd & $137.00 \pm 24.95$ & $190.55 \pm 68.27$ & $266.27 \pm 93.04$ & ${ }^{c} 0.001^{* *}$ \\
\hline & Median & 133.00 & 189.00 & 265.50 & \\
\hline \multirow{2}{*}{$\begin{array}{l}\text { Mean platelet volüme } \\
\text { (femtolitre) }\end{array}$} & Mean \pm Sd & $7.36 \pm 0.53$ & $8.23 \pm 1.39$ & $8.59 \pm 1.03$ & ${ }^{c} 0.002^{* *}$ \\
\hline & Median & 7.15 & 8.10 & 8.40 & \\
\hline
\end{tabular}


cholesterol and C- peptide; in patients with hemodialysis and peritoneal dialysis treatment (p>0.05) (TABLE 4).

No statistically significant difference was shown the between levels of MPV with the levels of urea, creatinine, hemoglobin, HOMAIR, BMI, LDL- cholesterol, HDL cholesterol and $\mathrm{C}$ - peptide; in the control group ( $\mathrm{p}>0.05)$. Positive correlation was demonstrated the between MPV levels with the number of platelets; in the control group ( the relationship between was found to be $82,3 \%)(r=0.823$; $\mathrm{p}=0.001 ; \mathrm{p}<0.01)($ TABLE 4).

Mann-WhitneyUTest performed to determine the difference; platelet values were determined higher in hemodialysis and peritoneal dialysis patients than in the control group $(\mathrm{p}=0.005$; $\mathrm{p}=0.001 ; \mathrm{p}=0.001 ; \mathrm{p}<0.01)$; platelet values were determined higher in the peritoneal dialysis groups than in hemodialysis group ( $\mathrm{p}=0.001$; $\mathrm{p}<0.01$ ) (TABLE 5). According to the groups; MPV variable was found to be statistically significant $(\mathrm{p}=0.002 ; \mathrm{p}<0.01)$. According to the results of Mann-Whitney U Test performed to determine the difference; MPV values of the patients in hemodialysis, peritoneal dialysis were determined to be statistically significantly higher compared to MPV values of the cases in control groups $(\mathrm{p}=0.024 ; \mathrm{p}=0.001 ; \mathrm{p}<0.05)$ (TABLE 5).

\section{Discussion}

Declines of glomerul filtration rate cause to progressively increase of athero-thrombotic risk and platelet function disorders and cardiovascular diseases risk.Recently; it is suggested that larger platelets are used to be as a biomarker for predictive of cardiovascular disease risk. Also; increase of the platelet size contribute to increasing risk of cardiovascular disease; in every-stage of chronic renal disease $[13,14]$.

Mean platelet volum is an indicator of platelet function and platelet activity.Also; mean platelet volum correlates with beta- thromboglobulin release and thromboxane synthesis and adhesion molecule expression.Many studies have been shown that mean platelet volum plays an important role for the development of endothelial injury and endothelial dysfunction. Mean platelet volum levels increase in certain vascular risk factor states. Also; increase of mean platelet volum is determined in the existense of many disease such as obesity, microalbuminuria, hypercholesterolemia, acute myocardial infarction, glucose metabolism disorders, stroke and cardiovascular disease etc.

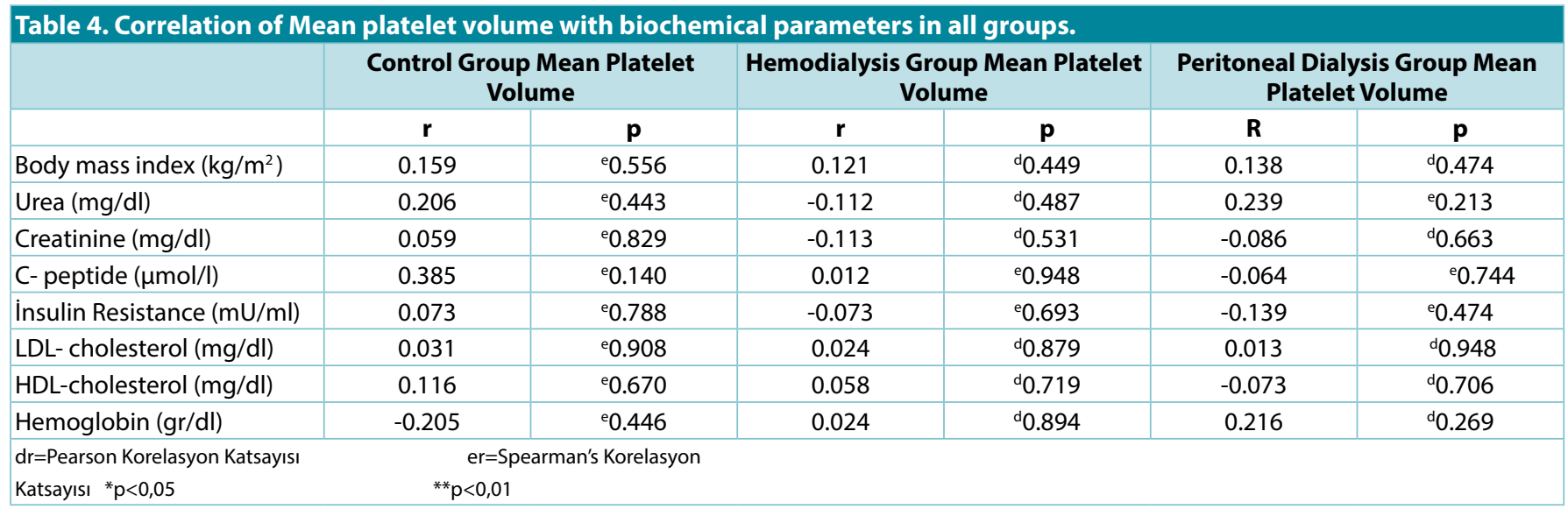

\begin{tabular}{|c|c|c|c|}
\hline & $\begin{array}{l}\text { Control and Hemodialysis } \\
\text { Groups }\end{array}$ & $\begin{array}{c}\text { Control and Peritoneal Dialysis } \\
\text { Groups }\end{array}$ & $\begin{array}{c}\text { Hemodialysis and Peritoneal } \\
\text { Dialysis Groups }\end{array}$ \\
\hline cvx Body mass index $\left(\mathrm{kg} / \mathrm{m}^{2}\right)$ & 0.079 & $0.014^{*}$ & 0.550 \\
\hline LDL- cholesterol (mg/dl) & 0.085 & 0.170 & $0.002^{* *}$ \\
\hline HDL-cholesterol (mg/dl) & $0.009^{* *}$ & 0.104 & 0.754 \\
\hline Mean platelet Volume (femtolitre) & $0.024^{*}$ & $0.001^{* *}$ & 0.142 \\
\hline
\end{tabular}


[15]. Especially; MPV levels can be important for predict an outcome following cardiovascular diseases [16]. Some studies demonstrated that age, fasting plasma glucose and serum creatinine effected on MPV; in patients with type 2 diabetes mellitus [17]. Apart from; it was found that correlated to be the between body mass indices with elevated mean platelet volum; in obese patients. İn this study was determined that weight loss might cause to the reduction of MPV; in obese patients $[18,19]$. Similarly; MPV correlated with waist circumference and body mass indices and platelet count; in patients with metabolic syndrome. We aimed to demonstrate the differences of mean platelet volum levels; the betwen peritoneal dialysis patients with hemodialysis patients. However; we tried to determine the association between an important contibutors such as biochemical parameters and hemoglobin, platelet and some metabolic parameters with MPV, in dialysis patients.

İn our study was found to be higher body mass indices, plazma LDL-cholesterole and C-peptide levels in peritoneal dialysis patients than in hemodialysis patients and the control group. Currently; glucose- containing peritoneal dialysis solutions (PDF) are used in peritoneal dialysis treatment and it is suggested that due to glucose containing of PDF may lead to the metabolic disorders include weight gain, dyslipidemia, insulin resistance and worsened glycemic control; when used for a long time [20]. Although; plazma C-peptide levels of patients with peritoneal dialysis were determined to be more higher than other groups. C- peptid is secreted from proinsulin. C- peptide and it' effects on adipos tissue regulate the synthesis of adipocytokine; in visceral adipose tissue. Also; C- peptide controls the inflammatory and macrocirculation and microcirculation and glomerular filtration. C-peptide at the concentrations above physiological is proinflammatory effects. Recently; it has been thought that can be the association between plazma C-peptide levels with obesite [21]. İn many studies were demonstrated that elevated plazma C- peptid levels could contribute to the development of type 2 diabetes mellitus and atheroscklerosis. İn our study; elevated of plazma C- peptid levels could show increase of atheroscklerosis risk and increase of the development risk of type 2 diyabetes mellitus; in peritoneal dialysis patients.

İn this study, insulin resistance was found in the normal range, in the control and dialysis groups. This condition might explained by lack of obesitiy and in the normal range of fasting blood glucose, in the control and dialysis groups.

We found to be in the range of normal value the levels of MPV, in the dialysis and control groups. As well as; in our study was demonstrated to be elevated of MPV levels in peritoneal dialysis patients and in hemodialysis patients; when compared with MPV levels of the control group. İn some studies; positive correlation is shown the between MPV levels with declines of glomerul filtration. Loss of renal function of the hemodialysis and peritoneal dialysis groups might cause to the changes of MPV levels, in our study. İ is suggested to be the relationship between larger platelets with endotelial dysfunction, vascular injury and atheroscklerosis. İ additionally; it is known that increase of chronic inflammation, endotelial injury and atheroscklerosis risk seen in dialysis patients. Accordingly; elevated MPV levels of dialysis patients could show to be increased of the risk of atheroscklerosis and cardiovascular disease, in our study. However; the association between was not demonstrated MPV with biochemical parameters, body mass indices and insulin resistance and C- peptide; in our study.Features of patients and determining the range of normal value MPV and lack not insulin resistance in our dialysis patients might cause to obtain these results.

İn our study, platelet counts of the dialysis and control groups were determined in the normal value range although; platelet counts of patients with peritoneal dialysis and hemodialysis were higher than the control group, compared to the groups. Platelets play a role in the thrombogenesis and they can cause to the development of atherogenesis and the progression of atheroscklerotic lesions. Platelets contribute to the structure of atheroma formation and trombosis in many vascular diseases such as peripheral, coronary, cerebrovascular. We thought that the increase of platelet count of dialysis patients might associated with a higher risk of atheroscklerosis; when compared with the control group $[19,20]$. Mean platelet volum levels associated with the average size of platelets and increase of production of platelets. Therefore; positive correlation might be determined to the between count of platelets with MPV, in our study.On the other hand; the relationship between was not found to MPV with platelet counts, in our 
dialysis patients. This state can be explained by the existence of various parameters effects such as anticoagulan treatment used, increase of bleeding risk and a consequence of the bloodmembrane contact, the number of platelets of dialysis patients.

\section{Limitations}

MPV as a marker of prognosis and predictive are uncertainty as to whether the relationship between platelet size and cardiovascular risk factors is continuous or categorical. The clinical using of MPV value in determining dialysis patients's cardiovascular risk factors [22]. Additionally; the MPV cut-off point is not known for predicting cardiovascular disease risk used; in clinical practice.

The timing and methods of blood sample preparation are an important factor for the measurement of MPV. İn this study; EDTA or citrate were used as an anticoagulant for blood sample preperation $[23,24]$. It is known that citrate can cause lower mean MPV values and EDTA can lead platelet sweelling ,as an anticoagulant used. The variability in the timining and methods, as an anticoagulants EDTA or citrate used can be effected on obtained results.

We believed that preperation of blood sample and the relationship between is not know MPV cut-off point with cardiovaskuler disease risk factors, altered our results. We thought that this condition can limitated to the results of our study.

\section{Summary and Conclusion}

we thought that increase of MPV levels could associated with the increase of atheroscklerosis and trombosis risk. Also; elevated MPV may associated with loss of renal function and etiology and pathology of chronic renal diseases; especially given regulary treatment and followed- up, in dialysis patients. İn our study was shown to be elevated MPV levels; in dialysis patients and this condition can be explained by the precense of inflammation. However; the relationship between was not demonstrated MPV levels with some metabolic parameters because; these metabolic parameters which can cause to development of inflammation such as; the existence of insülin resistance, elevetad C-peptid levels, dyslipidemia, elevetad blood glucose levels etc were controlled; in our patient groups.

The development of chronic renal diseases and then progress to end-stage renal diseases are multifactoriel. We think that this condition can effect on the acquisition of the different results association with MPV measurements. However; ratio of loss of renal functions, etiology of renal diseases and metabolic disorders may effect on measurement of MPV. We think that future studies need to show a clinical important of MPV.

\section{REFERENCES}

1. Silvia L, Alessio M, Gaspare ER et al. Cardiac,Inflammatory and Metabolic Parameters: Hemodialysis versus Peritoneal Dialysis. Cardiorenal. Med. 5(1), 20-30 (2015).

2. Bohn E, Tangri N, Gali B et al. Predicting risk of mortality in dialysis patients: a retrospective cohort study evaluating the prognostic value of a simple chest X-ray. BMC. Nephrol. 1(1), 14263 (2013).

3. Dervisoglu E, Kozdag G, Etiler N et al. Association of glomerular filtration rate and inflammation with left ventricular hypertrophy in chronic kidney disease patients. Hippokratia. 16(2), 137-142 (2012).

4. Wang AY, Wang M, Woo J et al. Inflammation, residual kidney function, and cardiac hypertrophy are interrelated and combine adversely to enhance mortality and cardiovascular deathrisk of peritoneal dialysis patients. J. Am. Soc. Nephrol. 15(8), 2186-2194 (2004).

5. Heng-Jung Hsu, Chiung-Hui Yen, I-Wen Wu et al. The Association of Uremic Toxins and Inflammation in Hemodialysis Patients. Plos.
One. 9(7), e102691 (2014).

6. Vizioli L, Muscari S, Muscari A. The relationship of mean platelet volume with the risk and prognosis of cardiovascular diseases. Int. J. Clin. Pract. 63(10), 1509-15 (2009).

7. Chu SG, Becker RC, Berger PB et al. Mean platelet volume as a predictor of cardiovascular risk:a systematic review and meta-analysis. $J$. Thromb. Haemost. 8(1), 148-156 (2010).

8. Srinivas CN, Solomon SS, Pulimi S et al. Ethnic variation in certain hematological and biochemical reference intervals in a south Indian healthy adult population. Eur. J. Intern. Med. 19(1), 46-50 (2008).

9. Cao X, Xie X, Zhou J et al. Increased platelet volüme in a general population with prehypertension: a cross-sectional study of 80 545 participants from china. Hypertens. Res. 35(9), 903-908 (2012).

10. Ju HY, Kim JK, Hur SM et al. Could mean platelet volume be a promising biomarker of progression of chronic kidney disease?. Platelets. 26(2), 143-147 (2015)

11. Hale S, Esra B, Umut SB et.al. Mean Platelet Volume as a Potential Predictor of Renovascular
Thrombosis After Renal Transplant. Exp. Clin. Transplant. 11(1): 27-31 (2011).

12. Casserly LF, Dember LM. (2003) Thrombosis in end-stage renal disease. Semin. Dial. 16(3), 245-56.

13. Park Y, Schoene N, Harris W. Mean platelet volume as an indicator of platelet activation: methodological issues. Platelets. 13(5-6), 301306 (2002).

14. Bilen Y, Cankaya E, Keles M et al. Does decreased mean platelet volume predict inflammation in chronic renal failure, dialysis, and transplanted patients? Ren. Fail. 36(1), 69 72 (2014).

15. Esen B, Atay AE, Gunoz N et al. The relation of mean platelet volume with microalbuminuria and glomerular filtration rate in obese individuals without other metabolic risk factors: the role of platelets on renal functions. Clin. Nephrol. 83(6), 322-9 (2015).

16. Bath PM, Butterworth RJ. Platelet size: measurement, physiology and vascular disease. Blood. Coagul. Fibrinolysis. 7(2), 157-61 (1996).

17. Zhonghua YXZZ. Variance of mean platelet 
volume in subjects with normal glucose tolerance, impaired glucose regulation and type 2 diabetic mellitus and its relationship with diabetic peripheral artery disease.Pub. Med. 92(4), 232-5 (2012).

18. Coban E, Yilmaz A, Sari R. The effect of weight loss on the mean platelet volume in obese patients. Platelets. 18(3), 212- 6 (2007).

19. Furman-Niedziejko A, Rostoff P, Rychlak R et al. Relationship between abdominal obesity, platelet blood count and mean platelet volume in patients with metabolic syndrome. Folia.
Med. Cracov. 54(2), 55-64 (2014).

20. Skubala A, Zywiec J, Zelobowska K et al. Continuous glucose monitoring system in 72-hour glucose profile assessment in patients with end-stage renal disease on maintenance continuous ambulatory peritoneal dialysis. Med. Sci. Monit. 16(2), 75-83 (2010).

21. White JG. Platelets and atherosclerosis. Eur. J. Clin. Invest. 24(S1), 25-29 (1994).

22. Burr ML, Holliday RM, Fehily AM et al. Haematological prognostic indices aftermyocardial infarction: evidence from the diet and reinfarction trial (DART). Eur. Heart. J. 13(2), 166-170 (1992).

23. Boos CJ, Balakrishnan B, Lip GY. The effects of coronary artery disease severity on time dependent changes in platelet activation indices in stored whole blood. J. Thromb. Thrombolysis. 25(2), 135-140 (2008).

24. Cameron HA, Phillips R, Ibbotson RM et al. Platelet size in myocardial infarction. Br. Med. J. 287(6390), 449-451 (1983) 